\title{
Fast dispersive liquid-liquid microextraction based on magnetic retrieval of in situ formed an ionic liquid for the preconcentration and determination of benzophenone-type UV filters from environmental water samples
}

\author{
Justyna Ziemblińska-Bernart ${ }^{1} \cdot$ Iwona Nowak $^{1} \cdot$ Iwona Rykowska $^{1}$
}

Received: 10 May 2018 / Accepted: 2 November 2018 / Published online: 5 December 2018

(c) The Author(s) 2018

\begin{abstract}
This work concerns the development of a novel and rapid in situ dispersive liquid-liquid microextraction method for magnetic retrieval of ionic liquid as a new approach for the separation of benzophenone type (BP-type) UV filters via quantification using UPLC with PDA detection. The analytes determined in this study were a group of three benzophenones: 2,4-dihydroxybenzophenone (BP1), 2,2',4,4'-tetrahydroxybenzophenone (BP2) and 2-hydroxy-4-metoxybenzophenone (BP3). The hydrophilic ionic liquid found suitable for use as an extraction solvent of the targeted analytes was didecyldimethylammonium chlorate (DDAC). An anion exchanger, $\mathrm{NaClO}_{4}$ was added to promote a metathesis reaction and in situ formed the IL, [DDA $]\left[\mathrm{ClO}_{4}\right]$. The experimental parameters such as the concentration of IL, the molar ratio of DDAC to $\mathrm{NaClO}_{4}$, amount of iron oxide added and volume of water sample were investigated and optimised using a step-by-step optimisation process. The optimum experimental parameters were as follows: $30 \mathrm{~mL}$ of sample volume, $1 \%$ concentration of DDAC, the molar ratio of DDAC to $\mathrm{NaClO}_{4}-1: 2$, and $5 \mathrm{mg}$ of $\mathrm{Fe}_{3} \mathrm{O}_{4}$ magnetic nanoparticles. The proposed extraction method is simple and requires no more than $5 \mathrm{~min}$. The detection limit (LOD) obtained for target analytes ranged from $12.320 .0 \mathrm{ng} \mathrm{L}^{-1}$, while the correlation coefficient $\left(r^{2}\right)$ was from 0.9995 to 0.9999 . Finally, the developed method was successfully applied to the determination of BP-type UV filters in environmental water samples, and satisfactory results were obtained.
\end{abstract}

Keywords Ionic liquid · Magnetic nanoparticles · In situ MR IL-DLLME · BP-type UV filters · Benzophenones

\section{Introduction}

The intensity of solar UV radiation has increased in recent years due to damage to the ozone layer [1]. Excessive exposure to UV radiation carries many risks for the human body. Depending on the wavelength of radiation dose and exposure time, UV radiation causes different effects. UVA and UVB radiation (280-400 nm) penetrates deeply into layers of the skin, causing erythema and direct damage to the DNA structure [2]. They are also responsible for photoaging and indirect photoallergic reactions [3-6]. Many cosmetic products contain organic UV filters in their formulas to protect

Justyna Ziemblińska-Bernart

justyna.ziemblinska@amu.edu.pl

1 Department of Analytical Chemistry, Faculty of Chemistry, Adam Mickiewicz University in Poznań, Umultowska 89b Street, 61-614 Poznan, Poland the skin from harmful solar radiation. These compounds are aimed to absorb, reflect and scatter UV radiation. They are commonly used in many cosmetics, such as skin creams and lotions for tanning, face creams, lipsticks, hair sprays and shampoos [7]. The proportion of the UV filter of each formulation determines the sun-protection factor (SPF) [8], which is the indicator of the efficiency of sunscreen products.

The widespread inclusion of UV filters in personal care and consumer products increases human exposure to these increasingly widely used contaminants. Today, a significant amount of food packages, plastics and textiles contain UV filters to prevent polymer degradation and loss of food quality [9]. The occurrence of these organic contaminants has been reported in several matrices such as surface water [10-13], wastewater [14, 15] and seawater [16-18]. UV filters are widely used in commercial products, such as fragrances, insecticides, agricultural chemicals, 
pharmaceuticals, cosmetics and as additives for plastic. The European Union (EU) currently permits the use of 26 organic UV filters in cosmetic formulas [19]. BP-type UV filters can be released into the environment directly or indirectly. Their continuous input into the environment may lead to an accumulative negative effect on ecospecies and human beings. Benzophenones are one of the most used groups of UV filters. It is proven that benzophenone 1, 2 and 3 accumulate in living organisms and impair the operation of the endocrine system or reproductive tract disorders, demonstrating estrogenic activity [20-22]. The UV filters enter the human body mainly through the food chain [23] and dermal absorption [24]. Human biotransformation of BPs depends mostly on the exposure pathway. These compounds are mainly transformed into $\beta$-d-glucuronide and sulfate derivatives, which are excreted in urine. However, the metabolic excretory system is not $100 \%$ effective, and thus BP-type UV filters may accumulate in different human matrices, such as serum, adipose tissue, placenta [9], breast milk [25], hair and menstrual blood [26].

Quantification analysis of the radioprotective compounds is hampered by the presence of trace amounts of these compounds in environmental water samples, in the order of several $\mathrm{ng} \mathrm{L}^{-1}$. Additionally, analysis of environmental samples shows that the content of these compounds is $2-20$ times lower than predicted. The reason for this variation was explained in Straub's work [27], taking into account biodegradation, absorption on active sludge or abiotic degradation. Analysis of surface water in Switzerland and South Korea in 2010 showed the presence of UV filters (BP-4 and 4-MBC) up to several $100 \mathrm{ng} \mathrm{L}^{-1}$ [28]. What is more, the presence of radiosensitive substances in living organisms in the Glatt River in Switzerland was detected, i.e. shellfish-Dreissen polymorpha, fish-Barbus barbus, and cormorant—Phalacrocorax sp. In 2006 in some lakes and rivers of South Korea, benzophenones and their metabolites were detected at $47-87 \mathrm{ng} \mathrm{L}^{-1}$ concentrations [29]. Significantly higher levels of these compounds-up to several $\mu \mathrm{g} \mathrm{kg}^{-1}$, were discovered in bottom sediments.

UV filters must emit the energy absorbed by UV absorption, resulting in numerous non-destructive molecule reactions: fluorescence, phosphorescence, reversible isomerisation or destructive: fragmentation, radical generation and persistent isomerisation [30]. Organic UV filters can undergo numerous processes due to interaction with the sample matrix, e.g. due to chlorine action, BP3 undergo chlorination reaction to mono- and dichloro-derivatives and also decomposes to more stable methoxyphenol derivatives. Products produced during photodegradation may exhibit increased toxicity, e.g. the primary metabolite of BP3 is BP1 which shows greater estrogenic activity [31].

The ionic liquids (ILs), emerged as a new generation of solvents, are ionic compounds formed from a combination of large organic cations and various organic or inorganic anions, defined in the literature [32-35] as salts with melting points below $100{ }^{\circ} \mathrm{C}$. Physical and chemical properties of ionic liquids are mainly dependent on the construction of ionic compounds, size, arrangement and nature of both ions [36]. Any prospect of designing structures of the ionic liquids, by appropriate selection of the cation and anion, and thus give the corresponding physicochemical properties, provides the possibility of using these compounds in academic research as well as industrial applications [37, 38]. ILs are characterised by several outstanding features such as negligible vapour pressure, high thermal stability, the wide temperature range of liquid state, relatively high viscosity and ability to dissolve a broad and diverse range of compounds [36]. The ILs are known for their excellent salvation properties, negligible vapour pressure, relatively low toxicity, and thus they are widely recognised as green solvents. A special subclass of ILs is magnetic ionic liquids (MILs) that exhibit a strong magnetic susceptibility when exposed to an external magnetic field. These special ILs contain a paramagnetic atom in the IL structure (e.g. Fe(III), Mn(II), $\mathrm{Co}(\mathrm{II}), \mathrm{Gd}(\mathrm{III}), \mathrm{Dy}(\mathrm{III}), \mathrm{Ho}(\mathrm{III}))$, which is the responsible for their paramagnetism [39].

The ionic liquids have been nowadays successfully used in many effective microextraction techniques [40-46]. One of them is dispersive liquid-liquid microextraction (DLLME). Initially, the ionic liquids have been applied to the DLLME technique by Zhou and coworkers. This method was named IL-DLLME [47]. Recently, this technique was repeatedly modified by, e.g. manipulating of the sample temperature, using ultrasound, microwaves, centrifugation of the sample or further-reaching changes such as in situ IL-DLLME method. The in situ ionic liquids dispersive liquid-liquid microextraction method (in situ IL-DLLME) is a proposition of extraction methods which have been first proposed by Bahdadi and Shemirani in 2009, as in situ solvent formation microextraction (ISFME), applied to the determination of metals [48]. A similar approach has been utilised in the same year, for the determination of aromatic hydrocarbons, by Yao and Anderson [40]. The in situ IL-DLLME method is based on the dissolution of hydrophilic IL in an aqueous solution containing the analytes of interest, followed by the addition of an ion-exchange reagent forming an insoluble IL. An ionexchanger reagent promotes a metathesis reaction, and the hydrophilic IL is transformed into a hydrophobic IL which settles to contain the preconcentrated analytes [40]. The new idea was to use magnetic nanoparticles of iron oxide $\left(\mathrm{Fe}_{3} \mathrm{O}_{4}\right)$ for the retrieval of the in situ created ionic liquid [46]. Iron oxide was used as a sorbent to retrieve the IL that contained the analytes, which were then desorbed. MNPs have a large surface area and can be easily isolated from a sample solution using an external magnetic field [46, 49, 50]. The large interfacial area between the IL and the sample solution 
contributes to a faster mass transfer [51]. The application of MNPs in in situ IL-DLLME would be another rapid, simple, effective and eco-friendly microextraction technique.

Microextraction techniques with the application of ILs play an important role in the field of determination of organic UV filters in environmental water samples. Mei et al. [52] proposed the use of a polymeric IL-based monolith doped with magnetic nanoparticles as extraction phase for magnetic IT-SPME. Vidal et al. [53] used single drop microextraction with an IL as extraction phase rather than conventional organic solvents for the same purpose. Oenning et al. [54], Ge and Lee [55] for the extraction of UV filters have used imidazolium ionic liquid in hollow fibre liquid-phase microextraction (HFLPME). ILs as extraction solvents have also been utilised for DLLME extractions methods for UV filter determination with good extraction efficiency. First, Lee et al. [56], then Xue et al. [57], used IL-USA-DLLME, where the IL is dispersed more efficiently by the aid of ultrasonication. Ku et al. [58] proposed the employment of a mechanical shaker instead of ultrasounds, and recently Suarez et al. [59] proposed an ILMSA-DLLME approach. Chisvert et al. [39] introduced a new hybrid microextraction technique, termed stir bar dispersive liquid microextraction (SBDLME), where a magnetic ionic liquid (MIL) is used as extraction phase. This novel approach was applied to the determination of eight UV filters in bathing waters with good analytical features.

Used in the research ILs belong to quaternary ammonium salts (qats) and are known as a quaternary-based ionic liquid (quat-based ILs). The novelty of the work is the use of ammonium-based ILs instead of widely studied imidazolium-based ILs [40-48]. The method predicts use of quat-based ILs with didecyldimethylammonium chloride (DDAC) as a hydrophilic ionic liquid, which is a base to create in situ new, hydrophobic IL, didecyldimethylammonium perchlorate [DDA] $\left[\mathrm{ClO}_{4}\right]$. Quat-based ILs are synthesised in an easy, fast and economical way. The synthesis of these compounds is based on an anion exchange reaction (in an aqueous medium, at room temperature), of another commercially and widely available quat-based ionic liquid, i.e. [DDA] [Cl], [DDA] [Br] and [BA] [Cl] [60]. A simple and economical way to obtain this kind of ILs creates enormous potential for synthesis of new and unknown quat-based ILs.

This study aimed to introduce a novel and rapid ILDLLME method based on the magnetic retrieval of the in situ made ionic liquid (MR-IL) for the trace-level determination of three benzophenone-type UV filters in lake water samples. The in situ MR IL-DLLME method has been optimised, validated and used to analyse a group of three benzophenones, such as 2,4-dihydroxybenzophenone (BP1), 2,2',4,4'-tetrahydroxybenzophenone (BP2), 2-hydroxy-4-metoxybenzophenone (BP3).

\section{Experimental}

\section{Reagents and chemicals}

All reagents used during the experiments were of analytical grade or better. The group of three benzophenones used in this study (Table 1), 2,4-dihydroxybenzophenone (BP1, 99\%), 2,2',4,4'-tetrahydroxybenzophenone (BP2, 97\%) was purchased from Sigma-Aldrich (Poznań, Poland) and 2-hydroxy-4-metoxybenzophenone (BP3, 98\%) from Fluka (Poznań, Poland). The target standards were dissolved in methanol. Working standard solutions were prepared by diluting an appropriate amount of the standard stock solutions in methanol. HPLC-grade methanol $(\geq 99.9 \%)$ was

Table 1 The name, symbol, chemical formula, chemical structure and analytical wavelength of studied endocrine disrupting phenols

2-hydroxy-4-metoxybenzophenone (BP3) Chemical formula


purchased from Sigma-Aldrich (Poznań, Polska). Didecyldimethylammonium chloride [DDAC], used in the extraction of the ionic liquid, was supplied by Lonza (Mapleton, Illinois, USA). $\mathrm{NaClO}_{4}, \mathrm{FeCl}_{3} \cdot 6 \mathrm{H}_{2} \mathrm{O}$, and $\mathrm{FeSO}_{4} \cdot 7 \mathrm{H}_{2} \mathrm{O}$ were all purchased from Sigma-Aldrich (Poznań, Poland). $25 \% \mathrm{NH}_{3}$ was supplied by POCH S.A. (Gliwice, Poland). Argon of 99.9992\% purity was obtained from Air Products (Poznań, Poland). The deionised water was purified using water deionizer obtained from Hydrolab (Gdańsk, Poland).

\section{Preparation of $\mathrm{Fe}_{3} \mathrm{O}_{4}$ magnetic nanoparticles}

$\mathrm{Fe}_{3} \mathrm{O}_{4}$ magnetic nanoparticles were synthesised by the chemical co-precipitation in the presence of ammonia in accordance to the method reported by Liu et al. [61]. $1.5 \mathrm{~g}$ $\mathrm{FeCl}_{3} \cdot 6 \mathrm{H}_{2} \mathrm{O}$ and $1.5 \mathrm{~g} \mathrm{FeSO} \cdot 7 \mathrm{H}_{2} \mathrm{O}$ were dissolved in $40 \mathrm{~mL}$ of deionised water under argon gas at $80{ }^{\circ} \mathrm{C}$ for 45 min with stirring. Then, $25 \mathrm{~mL}$ of $25 \% \mathrm{NH}_{3}$ was slowly added to the solution using pipette with vigorous stirring. The colour of the solution turned from orange to black, nanoparticles of magnetite were formed immediately. The black solid was washed several times with deionised water, once with $0.02 \mathrm{M}$ sodium chloride and twice with methanol. Magnetic nanoparticles were separated using a neodymium magnet and then dried at room temperature. Scanning electron microscope SU3500 from Hitachi with BSE-3D detector was used to verify the structure and size of $\mathrm{Fe}_{3} \mathrm{O}_{4}$ nanoparticles. Figure 1 shows SEM photos of the $\mathrm{Fe}_{3} \mathrm{O}_{4}$ MNPs in an aggregation forms due to their magnetic features. Single nanoparticles exhibited nearly spherical morphology with good dispersity and an average diameter of $150 \mathrm{~nm}$.

Magnetic $\mathrm{Fe}_{3} \mathrm{O}_{4}$ nanoparticles have gained wide acceptance in separation science, because of their advantages, such as simple, cost-effective and high-yielding preparation method, good adsorption capacity, superparamagnetism and low toxicity [61, 62]. Hydrophobic MNPs were used as sorbents to retrieve the extractant (in situ formed IL) that extract the analytes, which were then desorbed from the nanoparticles by dissolving in an organic solvent. Both positively and negatively charged magnetic nanoparticles interact with the positively charged cation of the ionic liquid. A distinct advantage of $\mathrm{Fe}_{3} \mathrm{O}_{4}$ nanoparticles is their superparamagnetism, what allows them to be easily isolated from a sample solution using an external magnetic field. MNPs have a large surface area, a large interfacial area between the extractant and the sample, and therefore contribute to a faster mass transfer.

\section{Instrumentation}

UPLC-PDA analysis was carried out using an Acquity UPLC System from Waters connected with a PDA detector an automatic sample injector, from Waters Sp. z o.o. (Warsaw, Poland). $6 \mu \mathrm{L}$ samples were injected into an Acquity UPLC® HSS T3 $(100 \mathrm{~mm} \times 2.1 \mathrm{~mm} ; 1.8 \mu \mathrm{m})$ column from Waters. The mobile phase used for the analysis was a methanol-water mixture $60 / 40(\mathrm{v} / \mathrm{v})$ at a flow rate of $0.4 \mathrm{~mL} \mathrm{~min}^{-1}$. The column temperature was $25^{\circ} \mathrm{C}$. Typical chromatogram of the target organic UV filters is shown in Fig. 2. The analytical wavelength of three benzophenones was analysed. According to the results, the wavelength of UPLC analysis was determined at $290 \mathrm{~nm}$.

\section{In situ IL-DLLME with magnetic retrieval of ionic liquid procedures}

A portion of $5 \mathrm{mg}$ of $\mathrm{Fe}_{3} \mathrm{O}_{4}$ magnetic nanoparticles and $400 \mathrm{mg}$ of ionic liquid was added to a glass tube. Then, $30 \mathrm{~mL}$ of water sample was poured into the vial. The mixture was vigorously shaken till total dissolving of the IL. Subsequently, $800 \mu \mathrm{L}$ of $\mathrm{NaClO}_{4}$ solution was added to initiate the metathesis reaction. As a result, hydrophobic IL,
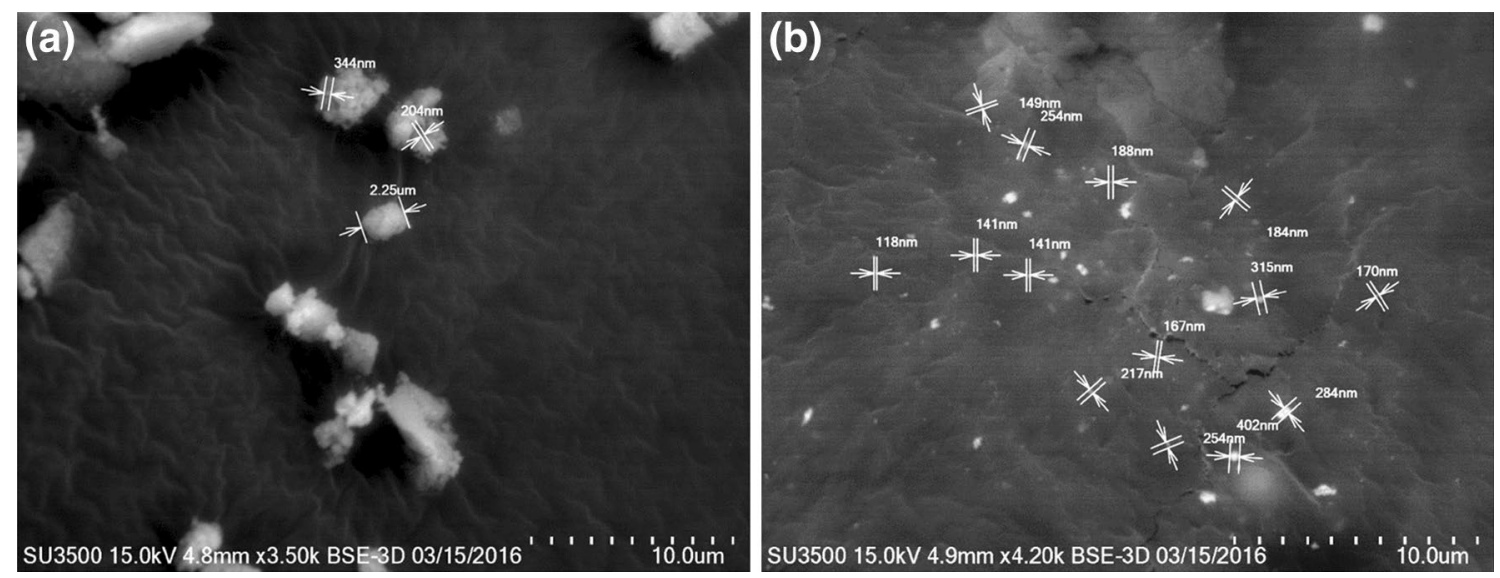

Fig. 1 SEM images of $\mathrm{Fe}_{3} \mathrm{O}_{4}$ magnetic nanoparticles; a aggregation forms and $\mathbf{b}$ single nanoparticles 


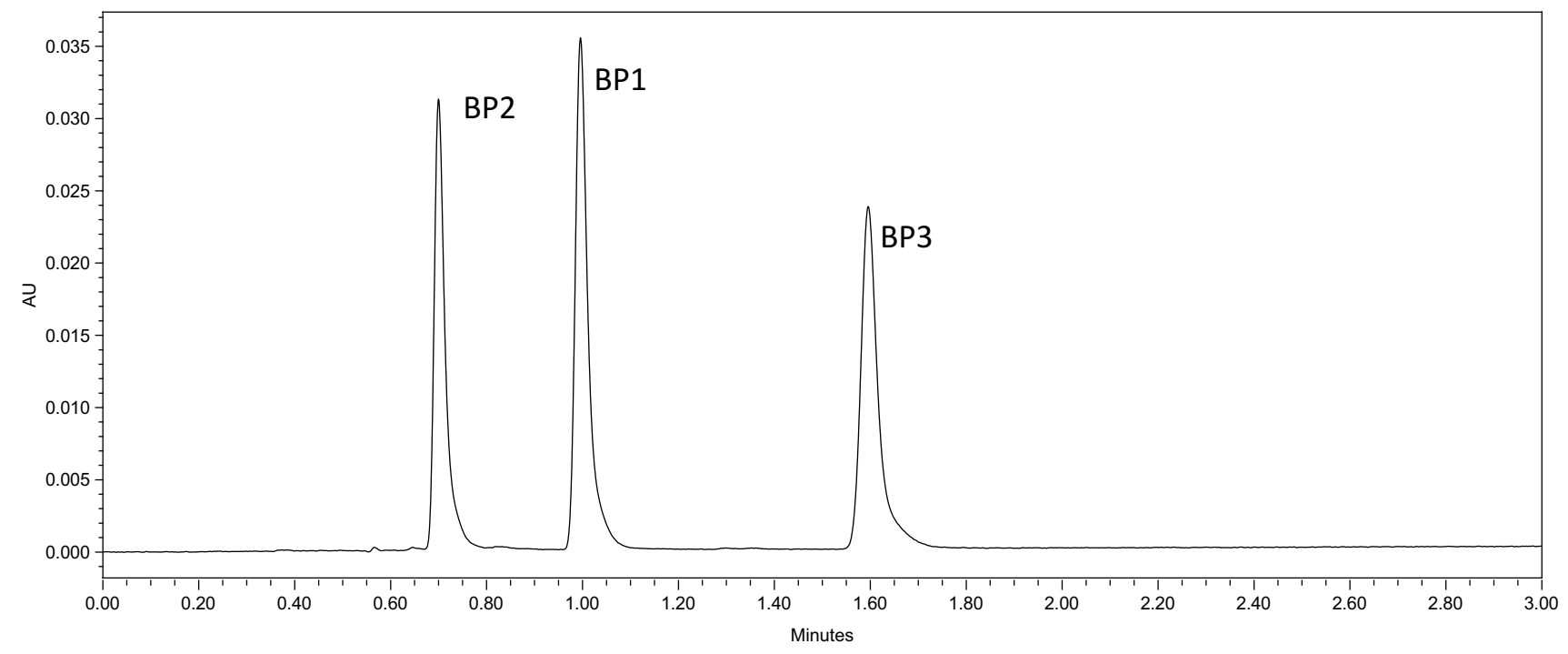

Fig. 2 Typical chromatogram of the three BP-type UV filters: 2,2',4,4'-tetrahydroxybenzophenone (BP2), 2,4-dihydroxybenzophenone (BP1), 2-hydroxy-4-metoxybenzophenone (BP3)

didecyldimethylammonium perchlorate $[\mathrm{DDA}]\left[\mathrm{ClO}_{4}\right]$ was formed in situ. The mixture was stirred for $2 \mathrm{~min}$. Then, the neodymium magnet was held around the tube to collect the MNPs with the ionic liquid containing target analytes. The water phase was then removed, and the magnetic nanoparticles with the IL phase were dissolved in $500 \mu \mathrm{L}$ portion of methanol. Finally, MNPs were isolated by magnetic decantation. The target analytes were then determined using UPLC-PDA analysis.

\section{Method performance}

A step-by-step optimisation was conducted to obtain satisfactory enrichment factors $\left(\mathrm{Ef}_{\mathrm{s}}\right)$ and recovery rates, including a dosage of $\mathrm{MNPs} \mathrm{Fe}_{3} \mathrm{O}_{4}$ and ionic liquids. The molar ratio of $\mathrm{IL}: \mathrm{NaClO}_{4}$ was optimised in the previous analysis as 1:2. Optimal extraction parameters were selected based on the applied Snedecor-Fisher's F-statistic test and Student's $t$ statistic test. Statistical tests were applied at each stage of optimisation, at the significance level of $\alpha=0.05$. The $\mathrm{Ef}_{\mathrm{s}}$ and recoveries were calculated using the following equations:

$\mathrm{Ef}=\frac{C_{\mathrm{IL}}}{C_{\text {water }}}$,

$R \%=\frac{C_{\mathrm{IL}} \times V_{\mathrm{IL}}}{C_{\text {water }} \times V_{\text {water }}}$,

where $\mathrm{EF}$ is the enrichment factor, $R \%$ is the recovery, $C_{\mathrm{IL}}$ isthe concentration of analytes in the extraction solvent, $V_{\mathrm{IL}}$ is the volume of the extraction solvent, $C_{\mathrm{water}}$ is the concentration of analytes in the water sample and $V_{\text {water }}$ is the volume of the water sample, respectively.

The in situ MR IL-DLLME technique was evaluated using the optimised conditions, based on linearity, the limit of detection (LOD), the limit of quantitation (LOQ) and the recovery under the optimised conditions. A calibration curve range was tested at five levels. The LOD was calculated as three times the signal-to-noise ratio $(S / N=3)$, and LOQ was calculated as ten times the signal-to-noise ratio $(S / N=10)$. A blank test was carried out to verify the possibility of contamination. The extraction efficiency was calculated as average recovery at different concentration levels.

The ionic strength of the medium may influence the extraction efficiency of benzophenones. In this case, the effect of the salt content must be evaluated, mainly considering that the present method is intended for real waters such as seawaters. The study was carried out in aqueous solutions (deionised waters) and 3.5\% (v/v) of $\mathrm{NaCl}$ (artificial seawaters). The matrix effect was evaluated by comparing the slope of the calibration curve for artificial spiked seawater with the slope of the calibration curve obtained for standards. The value of the quotient $>1$ indicated the signal enhancement but value $<1$ show the existence of signal suppression [42].

\section{Results and discussion}

\section{Selection and optimisation of the IL concentration}

The physicochemical properties of ILs depend on the type and size of the constituents of both their cations and anions. 
ILs are amphiphilic compounds with distinctly isolated hydrophobic and hydrophilic moieties: a polar or ionic group linked to a hydrocarbon long chain (linear, branched or aromatic). ILs molecules are present mainly in the form of monomers, but also small amounts of monomers and dimers can be noticed in dilute aqueous solution. When the surfactant concentration increases above a certain threshold, called the critical micelle concentration (CMC), surfactant monomers spontaneously combine to form a group of particles of a colloidal size, known as micelles. Micellar aggregates formed may have a variety of shapes, from layered, ellipsoidal to spherical [63]. Regardless of the assumed shape, the molecules orient themselves in such a way that the hydrocarbon chains form a non-polar core in the centre of the micelle. In this way, non-polar microenvironment in an aqueous medium is formed. Its role is to absorb hydrophobic and covalent compounds originally dissolved in the water sample. The whole extraction process is similar to the traditional liquid-liquid extraction (LLE), but with the difference, that due to the conversion of a homogeneous solution in a heterogeneous one, the "organic" phase is generated in the aqueous matrix by concentrating hydrophobic moieties dispersed in the aqueous phase previously [64]. Consequently, near $\mathrm{CMC}$, the formation of a hazy solution is observed. At this point, the surfactant phase is rich in hydrophobic compounds originally present in the aqueous matrix.

The concentration of DDAC was optimised to achieve the highest recovery of the target analytes (Fig. 3). The optimisation was carried out in the range from 0.5 to $5 \%$. The sample volume used for the optimisation process was $10 \mathrm{~mL}$. The number of magnetic nanoparticles was $5 \mathrm{mg}$. The concentration of IL has a significant impact on the extraction efficiency. Recovery values obtained for $0.5 \%$ of the IL concentration were low-not exceeding $70 \%$. Using higher concentration, $1 \%$ of DDAC, recovery values are much higher-above $90 \%$. Similar recovery values were obtained for $3 \%$ and $5 \%$ concentration of the IL. For

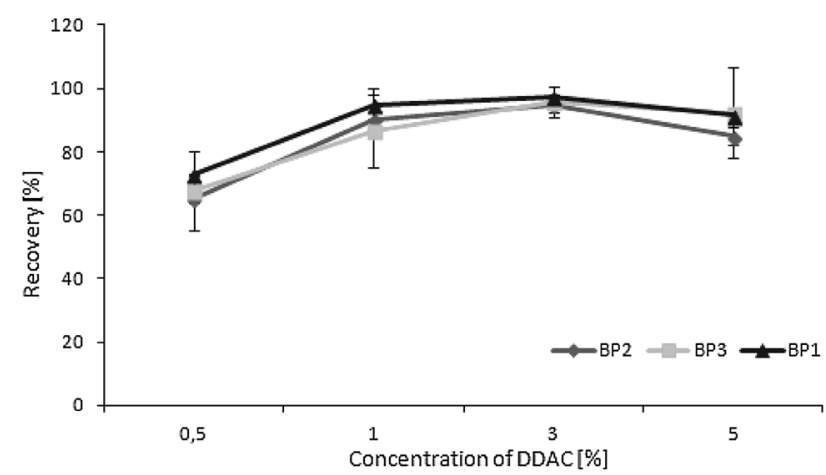

Fig. 3 Influence of the concentration of DDAC [\%] on the recovery of the target analytes. Method parameters: sample volume $10 \mathrm{~mL}$, the molar ratio of DDAC to $\mathrm{Fe}_{3} \mathrm{O}_{4}-1: 2, \mathrm{Fe}_{3} \mathrm{O}_{4}$ amount $5 \mathrm{mg}$ comparisons of recovery values for concentrations of $1 \%$ and $3 \%, 1 \%$ and $5 \%$, for both comparisons, the applied statistical tests did not show statistically significant differences. The optimum concentration of DDAC was established at $1 \%$ to reduce the addition of ionic liquid. Therefore, $1 \%$ of DDAC concentration was used in further tests.

\section{Optimisation of the molar ratio of DDAC to $\mathrm{NaClO}_{4}$}

The molar ratio of DDAC to $\mathrm{NaClO}_{4}$ was optimised for 5:1, 2:1, 1:1, 3:5 and 1:2 (Fig. 4). The highest increase in the recovery was noted for most studied benzophenones when the molar ratio was in the range from $1: 1$ to $1: 2$. The molar ratio of DDAC to $\mathrm{NaClO}_{4}$ was set at 1:2 to increase the efficiency of the extraction process. Excess addition of the ion exchanger ensures the metathesis reaction, and transformation of hydrophilic DDAC into a hydrophobic $[\mathrm{DDA}]\left[\mathrm{ClO}_{4}\right]$. Comparisons of recovery values for the molar ratio of DDAC to $\mathrm{NaClO}_{4}$, for both molar ratios of 1: 1 and $1: 2,3: 5$ and $1: 2$, showed statistically significant differences. The 1:2 molar ratio of DDAC: $\mathrm{NaClO}_{4}$ led to the best recovery results and was used in further experiments.

\section{Sample $\mathrm{pH}$ values}

Due to the fact that the $\mathrm{pH}$ value can affect the molecular form of the UV filters, the $\mathrm{pH}$ of each solution was always checked [65]. The $\mathrm{pH}$ value for all tested solutions was around 7.0. Because the $\mathrm{pH}$ lower than seven favours neutral forms of the UV filters and these forms are beneficial for the distribution of analytes into organic phase this value was assumed to be optimal for the extraction process.

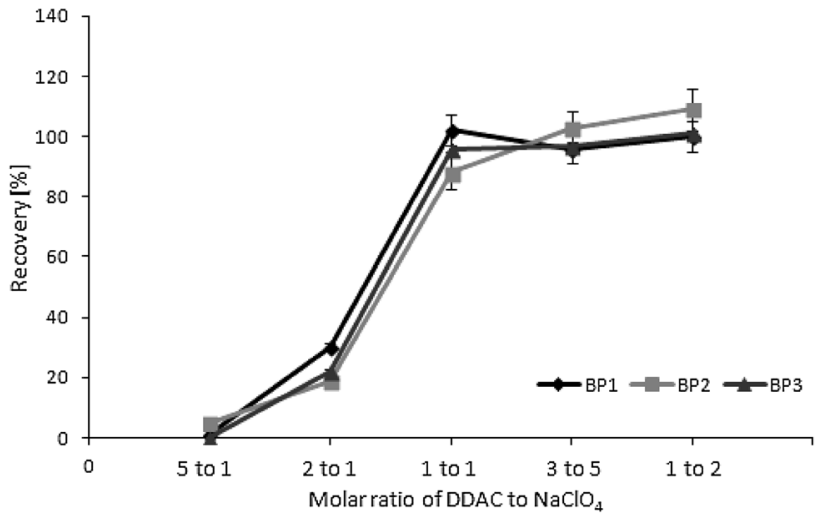

Fig. 4 Influence of the molar ratio of DDAC to $\mathrm{NaClO}_{4}$ on the recovery of the target analytes. Method parameters: sample volume $10 \mathrm{~mL}$, DDAC concentration $1 \%, \mathrm{Fe}_{3} \mathrm{O}_{4}$ amount $5 \mathrm{mg}$ 


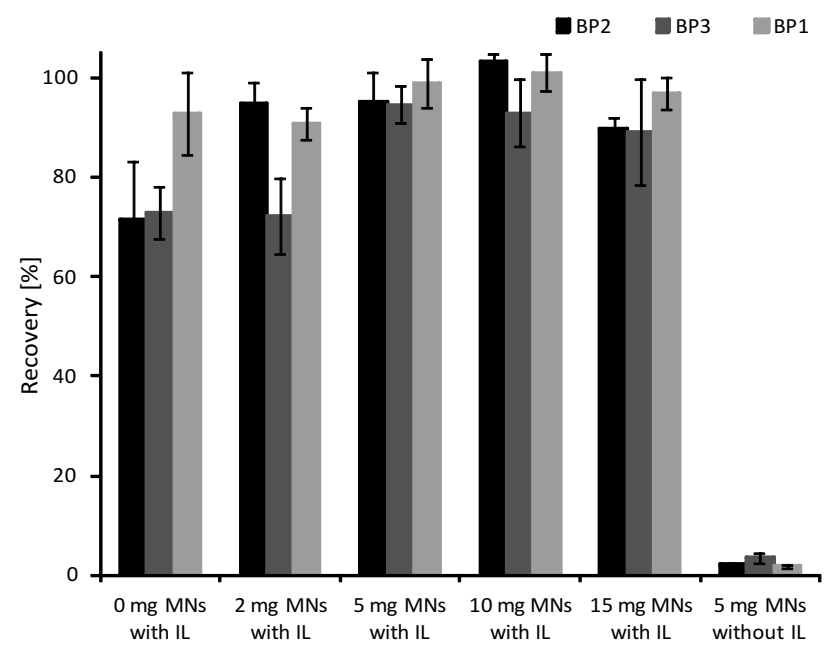

Fig. 5 Influence of the amount of $\mathrm{Fe}_{3} \mathrm{O}_{4}$ on the recovery of the target analytes. Method parameters: sample volume $10 \mathrm{~mL}$, DDAC concentration $1 \%$, the molar ratio of DDAC to $\mathrm{Fe}_{3} \mathrm{O}_{4}-1: 2$. Sample without $\mathrm{Fe}_{3} \mathrm{O}_{4}$ was centrifuged and cooled in an ice bath

\section{Selection and optimisation of MNPs amount}

The optimisation of $\mathrm{Fe}_{3} \mathrm{O}_{4}$ nanoparticles amount was carried out in the range from 0 to $15 \mathrm{mg}$ (Fig. 5). A sample with $5 \mathrm{mg}$ of MNPs and no IL was prepared to prove the $\mathrm{Fe}_{3} \mathrm{O}_{4}$ lack of extraction properties. The recovery of the target analytes from this sample was below 5\%, considerably higher recoveries received for samples with the IL addition. Similar results can be observed for the samples with $2 \mathrm{mg}$ of MNPs of iron oxide and without it. MNPs of $\mathrm{Fe}_{3} \mathrm{O}_{4}$ were used to separate in situ made hydrophobic IL from aqueous solution easily. Furthermore, in other in situ IL-DLLME methods, the IL formed during metathesis reaction sticks to the vial walls and it is difficult to collect it completely.

Moreover, the results obtained without $\mathrm{Fe}_{3} \mathrm{O}_{4}$ addition are profoundly less precise. As is evident in the figure, in the range from 10 to $15 \mathrm{mg}$ recoveries values slightly decreases with the increased amount of MNPs, it is most likely due to the excess MNPs not being effectively desorbed, which lowered the concentration of analytes. The optimization results of the MNPs amount parameter were assess statisticaly. For the comparison of recovery values for $\mathrm{Fe}_{3} \mathrm{O}_{4}$ amount, $2 \mathrm{mg}$ and $5 \mathrm{mg}$ of MNPs the applied statistical tests showed statistically significant differences, whereas for comparisons $5 \mathrm{mg}$ and $10 \mathrm{mg}$ and $5 \mathrm{mg}$ and $15 \mathrm{mg}$ did not differ significantly. The least manageable amount of iron oxide was used for further studies.

\section{Optimisation of sample volume}

Sample volume was optimised in the range from 10 to $40 \mathrm{~mL}$. In this study, the used concentration of IL was $1 \%$, the molar ratio of DDAC to $\mathrm{Fe}_{3} \mathrm{O}_{4-1}: 2$ and $\mathrm{Fe}_{3} \mathrm{O}_{4}$ amount was kept constant at $5 \mathrm{mg}$. The addition of methanol for the dissolution of the IL extracts adsorbed on the magnetic nanoparticles of $\mathrm{Fe}_{3} \mathrm{O}_{4}$ was optimised for $500 \mu \mathrm{l}$. The recovery values of the target analytes were at a similar level for most analysed compounds in the tested sample volume range (Fig. 6). $30 \mathrm{~mL}$ was selected as proper volume.

\section{Figures of merit of the in situ MR IL-DLLME method}

A validation was performed by determining a series of essential quality parameters such as calibration curve range, the linearity of the response calibration curves, the correlation coefficient $\left(r^{2}\right)$, the limits of detection (LOD) and quantification (LOQ), recovery and the enrichment factor (Ef) of the method under the optimised conditions (Table 2). The linearity of the method was examined using a mixed working solution of BP1, BP2, and BP3 in the concentration range of $1-1000 \mu \mathrm{g} \mathrm{L}^{-1}$. The calibration curves were linear in this range for all cases. The calculated calibration curves gave a high level of linearity, yielding coefficients of estimation of $\left(r^{2}\right)$ 0.9999, 0.9995, 0.9998 for BP1, BP2m and BP3, respectively. The LODs and LOQs, calculated as three times the signal-to-noise ratio $(S / N=3)$, and LOQ was calculated as ten times the signal-to-noise ratio $(S / N=10)$, were found to be in the low $n g \mathrm{~L}^{-1}$ level ranging from 12.3 to $20.0 \mathrm{ng} \mathrm{L}^{-1}$. These levels are higher than those reported in previously published papers dealing with the extraction of organic UV filters. The relative recoveries for the target UV filters ranged from 68.0 to $92.5 \%$. The repeatability of the method expressed as the percentage relative standard deviation (\%RSD) was evaluated for five replicate experiments with spiked seawater samples with UV filters at concentrations of $2.5 \mu \mathrm{g} \mathrm{L}^{-1}$ of each UV filter. The \%RSDs were below $4.8 \%$, illustrating satisfactory repeatability. The Ef ranged was obtained between 136 and 138 .

Further studies included assessment of the matrix effect. The overall optimised in situ MR DLLME method was

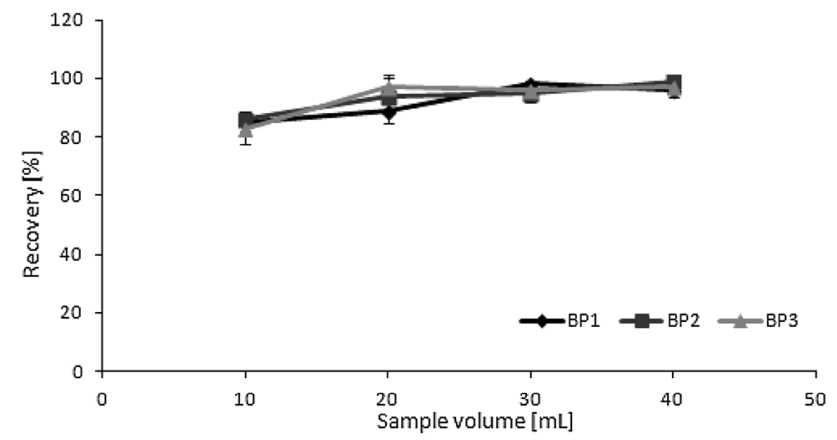

Fig. 6 Influence of the sample volume on the recovery of the target analytes. Method parameters: DDAC concentration $-1 \%$, molar ratio of DDAC to $\mathrm{Fe}_{3} \mathrm{O}_{4}-1: 2, \mathrm{Fe}_{3} \mathrm{O}_{4}$ amount $5 \mathrm{mg}$ 
Table 2 Figures of merit of the proposed in situ MR IL-DLLME method

\begin{tabular}{llll}
\hline Parameter & BP1 & BP2 & BP3 \\
\hline Calibration curve range $\left(\mu \mathrm{g} \mathrm{L}^{-1}\right)$ & $1-1000$ & $1-1000$ & $1-1000$ \\
Correlation coefficient $\left(r^{2}\right)$ & 0.9999 & 0.9995 & 0.9998 \\
Relative standard deviation $(\%)$ & 4.8 & 4.6 & 3.6 \\
Limit of detection $\left(\mu \mathrm{g} \mathrm{L}^{-1}\right)$ & 0.020 & 0.012 & 0.016 \\
Limit of quantitation $\left(\mu \mathrm{g} \mathrm{L}^{-1}\right)$ & 0.067 & 0.041 & 0.054 \\
Recovery (\%) $(\mathrm{RSD}[\%])$ & $70.5-90.3(3.4-2.9)$ & $68.0-92.5(7.8-5.4)$ & $79.5-91.3(3.5-1.3)$ \\
Enrichment factor & 135.5 & 138.8 & 137.0 \\
Matrix effect & 0.91 & 0.89 & 0.97 \\
\hline
\end{tabular}

Recoveries of target analytes were determined for spiked seawater samples at $2.5 \mu \mathrm{g} \mathrm{L}^{-1}$ and $12.5 \mu \mathrm{g} \mathrm{L}{ }^{-1}$ concentration of standards conducted with standards of UV filters dissolved in deionised water and artificial seawater $(3 \% \mathrm{NaCl})$ to verify the matrix effect. The matrix effect tested for all target analytes was of low significance, the values range from 0.89 to 0.97 .

The presented method was compared with several methods previously reported in the literature for the determination of UV filters to highlight the outstanding advantages of in situ MR IL-DLLME. According to Table 3, the proposed method is found better in the following ways: the use of MNPs substantially simplified the sample preparation process, the magnetic recovery of IL and analytes can be readily completed using a neodymium magnet rather than with tedious centrifugation. The in situ MR ILDLLME considerably accelerates the sample preparation procedure; the method is simple and requires no more than $5 \mathrm{~min}$ before instrumental analysis. The obtained values of the analytical ranges and LOD were found considerable better than those for other studies. The enrichment factor was also satisfactory and similar to the presented results of other microextraction methods. The proposed method reveals its vast potential and opens new opportunities in microextraction methods field. In conclusion, the in situ MR IL-DLLME method is simple, rapid and effective sample preparing technique.

Table 3 Comparison of the proposed in situ MR IL-DLLME method with other microextraction methods for determination of organic UV filters

\begin{tabular}{|c|c|c|c|c|c|c|c|}
\hline Method & Analyte & $\begin{array}{l}\text { Extraction } \\
\text { time (min) }\end{array}$ & Analytical method & $\begin{array}{l}\text { Analyti- } \\
\text { cal ranges } \\
\left(\mu \mathrm{L} \mathrm{L}^{-1}\right)\end{array}$ & LODs $\left(\mu \mathrm{g} \mathrm{L}^{-1}\right)$ & Ef & References \\
\hline IL-SDME $^{\mathrm{a}}$ & $\begin{array}{l}\text { BP3, IMC, MBC, OCR, } \\
\text { EDB, EMC }\end{array}$ & 45 & LC-UV & $1-300$ & $0.06-3.0$ & $8-98$ & [53] \\
\hline $\mathrm{SBSE}^{\mathrm{b}}$ & BP3 & 20 & LC-UV & $10-500$ & $2.4-30.6$ & $105-145$ & [66] \\
\hline IL-USA-DLLME $^{\mathrm{c}}$ & BP, BP3, EHS, HMS & 3 & HPLC-UV & $1-500$ & $0.2-5.0$ & $354-464$ & [56] \\
\hline IL-DLME $^{\mathrm{d}}$ & BP, 2-HMBP, 4-НBP & - & HPLC-UV & $10-1000$ & $1.9-6.4$ & $22-27$ & [67] \\
\hline in-syringe MSA-DLLME & $\begin{array}{l}\text { BP3, MBC, EDB, HMS, } \\
\text { EHS, OCR }\end{array}$ & 5.5 & HPLC-UV & up to 500 & $0.08-12$ & $11-23$ & [68] \\
\hline VAEME $^{\mathrm{f}}$ & $\mathrm{BP}, \mathrm{BP} 3$ & 10 & UHPLC-UV & $0.3-25$ & $1.3-1.5$ & - & [69] \\
\hline MSA-DLLME $^{g}$ & BP3 & 25 & HPLC-UV & $5-20000$ & $0.2-0.8$ & 59-107 & [65] \\
\hline SPME $^{\mathrm{h}}$ & $\begin{array}{l}\text { BP3, EHS, OD-PABA, } \\
\text { EHMC }\end{array}$ & 56 & HPLC-UV & $0.05-500$ & $0.006-0.061$ & - & {$[70]$} \\
\hline In situ MR IL-DLLME & BP1, BP2, BP3 & 5 & UPLC-PDA & $1-1000$ & $0.012-0.020$ & $136-139$ & This study \\
\hline
\end{tabular}

${ }^{\mathrm{a}} \mathrm{IL}-\mathrm{SDME}$ - ionic liquid-based single-drop microextraction

${ }^{\mathrm{b}} \mathrm{SBSE}$ - stir bar sorptive extraction

${ }^{\mathrm{c}}$ IL-USA-DLLME_-ionic liquid-based ultrasound-assisted dispersive liquid-liquid microextraction

${ }^{\mathrm{d}}$ IL-DLLME-ionic liquid dispersive liquid-liquid microextraction

${ }^{\mathrm{e}}$ in-syringe MSA-DLLME-in-syringe magnetic stirring-assisted dispersive liquid-liquid microextraction

${ }^{\mathrm{f}}$ VAEME-vortex-assisted emulsification microextraction method

${ }^{\mathrm{g}}$ MSA-DLLME-magnetic stirring-assisted dispersive liquid-liquid microextraction

${ }^{\mathrm{h}} \mathrm{SPME}$ — solid phase microextraction 


\section{Analysis of lake water samples}

To demonstrate the utility of the developed method, the proposed in situ MR IL-DLLME UPLC-PDA method was applied for the determination of three organic UV filters in the lake water samples. The optimised method was equally utilised for monitoring the water purity of selected six lakes in Poznań and Gniezno city in Poland, during the summer of 2016 (Table 4). Samples for analysis were collected in places constituting bathing areas, near the shore, where baths were mainly taken by children. The samples are taken at a depth of $15-30 \mathrm{~cm}$ below the water surface where the water is 1-1.5 m deep. Samples were collected from Lake Rusałka, Lake Strzeszyńskie, Lake Malta, Lake Świętokrzyskie, Lake Winiary and Lake Jelonek from public bathing beaches. Samples were collected in summer's months, in the first and second halves of each month.

The results of BP3 were under the limit of detection. Low concentration of BP3 may be caused by many factors, such as photodegradation or other processes such as biodegradation, abiotic degradation or absorption on bottom sediment. BP3 undergo chlorination reaction to mono- and dichloro-derivatives and also decomposes to more stable methoxyphenol derivatives. The major metabolite of BP3 is BP1 which exhibits even greater estrogenic activity [31]. The source of the determined UV filters was mainly sun care cosmetics, used in large quantities mainly during the summer when using the public bathing beaches. However, the concentrations of the three target benzophenones are still at trace-level.

\section{Conclusions}

In this study, the in situ dispersive liquid-liquid microextractions with magnetic retrieval of ionic liquid were utilised for separation of three BP-type UV filters such as 2,4-dihydroxybenzophenone, 2,2',4,4'-tetrahydroxybenzophenone and 2-hydroxy-4-metoxybenzophenone, successfully optimised using step-by-step analysis and further validated. The main extraction parameters were optimised as follows: the concentration of DDAC- $1 \%$, molar ratio of DDAC to $\mathrm{NaClO}_{4}-1: 2$, amount of added iron oxide $-5 \mathrm{mg}$ and sample volume $-30 \mathrm{~mL}$. The results indicate that the proposed separation technique is an effective tool for the determination of the target UV filters in aqueous solutions and was successfully applied for the determination of six lake water samples. This method provides high recoveries, good repeatability and could be successfully used for preconcentration of the organic UV filters from seawater samples. Furthermore, a significant reduction in extraction time to $5 \mathrm{~min}$, reagent addition, and energy consumption were also attained,

Table 4 Concentrations of three organic UV filters: BP1, BP2, and BP3 determined in six selected lake water samples in summer 2016

\begin{tabular}{|c|c|c|c|c|c|c|c|c|c|c|c|c|}
\hline \multirow{2}{*}{\multicolumn{3}{|c|}{$\frac{\text { Month/lake } \quad \text { L. Rusałka }}{\text { The concentration of BP1 }\left(\mu \mathrm{g} \mathrm{L}^{-1}\right) \pm \mathrm{SL}}$}} & \multicolumn{2}{|c|}{ L. Strzeszyńskie } & \multicolumn{2}{|l|}{ L. Malta } & \multicolumn{2}{|c|}{ L. Świętokrzyskie } & \multicolumn{2}{|c|}{ L. Winiary } & \multicolumn{2}{|c|}{ L. Jelonek } \\
\hline & & & & & & & & & & & & \\
\hline June I 2016 & $<$ LOD & - & $<$ LOD & - & $<\mathrm{LOD}$ & - & $<\mathrm{LOD}$ & - & $<\mathrm{LOD}$ & - & $<\mathrm{LOD}$ & - \\
\hline June II 2016 & 0.026 & \pm 0.003 & $<$ LOD & - & $<\mathrm{LOD}$ & - & $<\mathrm{LOD}$ & - & $<\mathrm{LOD}$ & - & $<\mathrm{LOD}$ & - \\
\hline July I 2016 & $<\mathrm{LOD}$ & - & $<$ LOD & - & 0.046 & \pm 0.005 & 0.039 & \pm 0.005 & 0.087 & \pm 0.010 & $<\mathrm{LOD}$ & - \\
\hline July II 2016 & $<\mathrm{LOD}$ & - & $<\mathrm{LOD}$ & - & 0.023 & \pm 0.003 & $<\mathrm{LOD}$ & - & 0.067 & \pm 0.008 & $<\mathrm{LOD}$ & - \\
\hline August I 2016 & $<\mathrm{LOD}$ & - & 0.058 & \pm 0.007 & 0.045 & \pm 0.005 & 0.033 & \pm 0.004 & $<\mathrm{LOD}$ & - & $<\mathrm{LOD}$ & - \\
\hline August II 2016 & $<$ LOD & - & 0.024 & \pm 0.003 & 0.029 & \pm 0.003 & $<\mathrm{LOD}$ & - & 0.026 & \pm 0.003 & 0.034 & \pm 0.004 \\
\hline \multicolumn{13}{|c|}{ The concentration of BP2 $\left(\mu \mathrm{g} \mathrm{L}^{-1}\right) \pm \mathrm{SD}$} \\
\hline June I 2016 & $<$ LOD & - & $<\mathrm{LOD}$ & - & $<\mathrm{LOD}$ & - & $<\mathrm{LOD}$ & - & $<\mathrm{LOD}$ & - & $<\mathrm{LOD}$ & - \\
\hline June II 2016 & $<\mathrm{LOD}$ & - & $<\mathrm{LOD}$ & - & $<\mathrm{LOD}$ & - & $<\mathrm{LOD}$ & - & $<\mathrm{LOD}$ & - & $<\mathrm{LOD}$ & - \\
\hline July I 2016 & $<\mathrm{LOD}$ & - & $<\mathrm{LOD}$ & - & $<\mathrm{LOD}$ & - & $<\mathrm{LOD}$ & - & $<\mathrm{LOD}$ & - & $<\mathrm{LOD}$ & - \\
\hline July II 2016 & 0.038 & \pm 0.001 & 0.094 & \pm 0.003 & 0.061 & \pm 0.002 & $<\mathrm{LOD}$ & - & $<$ LOD & - & 0.062 & \pm 0.002 \\
\hline August I 2016 & $<$ LOD & - & 0.028 & \pm 0.001 & 0.023 & \pm 0.001 & 0.014 & \pm 0.001 & 0.029 & \pm 0.001 & 0.029 & \pm 0.001 \\
\hline August II 2016 & 0.038 & \pm 0.001 & 0.036 & \pm 0.001 & 0.034 & \pm 0.001 & 0.019 & \pm 0.001 & $<\mathrm{LOD}$ & - & 0.039 & \pm 0.001 \\
\hline \multicolumn{13}{|c|}{ The concentration of BP3 $\left(\mu \mathrm{g} \mathrm{L}^{-1}\right) \pm \mathrm{SD}$} \\
\hline June I 2016 & $<\mathrm{LOD}$ & & & & & & & & & & & \\
\hline \multicolumn{13}{|l|}{ June II 2016} \\
\hline \multicolumn{13}{|l|}{ July I 2016} \\
\hline \multicolumn{13}{|l|}{ July II 2016} \\
\hline \multicolumn{13}{|l|}{ August I 2016} \\
\hline August II 2016 & & & & & & & & & & & & \\
\hline
\end{tabular}

$<$ LOD—found below the limit of detection 
contributing to the development of the new "green" extraction method.

Open Access This article is distributed under the terms of the Creative Commons Attribution 4.0 International License (http://creativeco mmons.org/licenses/by/4.0/), which permits unrestricted use, distribution, and reproduction in any medium, provided you give appropriate credit to the original author(s) and the source, provide a link to the Creative Commons license, and indicate if changes were made.

\section{References}

1. A.R. Abida, B. Marciniak, T. Pędziński, M. Shahida, J. Photochem. Photobiol. A. Chem. 332, 241 (2017)

2. D.R. Sambandan, D. Ratner, J. Am. Acad. Dermatol. 64, 748 (2011)

3. T. Suzuki, S. Kitamura, R. Khota, K. Sugihara, N. Fujimoto, S. Ohta, Toxicol. Appl. Pharmacol. 203, 9 (2005)

4. M. Schlumpf, B. Cotton, M. Conscience, V. Haller, B. Steinmann, W. Lichten-Steiger, Environ. Health Perspect. 109, 239 (2001)

5. R.S. Ma, B. Cotton, W. Lichtensteiger, M. Schlumpf, Toxicol. Sci. 74, 43 (2003)

6. R.H.M.M. Schreurs, E. Sonneveld, J.H.J. Jansen, W. Seinen, B. van der Burg, Toxicol. Sci. 83, 264 (2005)

7. J. Kockler, M. Oelgemöller, S. Robertson, B.D. Glass, J. Photochem. Photobiol. C Photochem. Rev. 13, 91 (2012)

8. N. Serpone, D. Dondi, A. Albini, Inorg. Chim. Acta 360, 794 (2007)

9. J. Valle-Sistac, D. Molins-Delgado, M. Díaz, L. Ibáñez, D. Barceló, M. Silvia Díaz-Cruz, Environ. Int. 88, 243 (2016)

10. R. Rodil, J.B. Quintana, P. López-Mahía, S. Muniategui-Lorenzo, D. Prada-Rodríguez, Anal. Chem. 80, 1307 (2008)

11. N. Negreira, I. Rodríguez, M. Ramil, E. Rubí, R. Cela, Anal. Chim. Acta 638, 36 (2009)

12. E. Magi, M. Di Carro, C. Scapolla, K.T.N. Nguyen, Chromatographia 75, 973 (2012)

13. H.T. Liu, L. Liu, Y.Q. Xiong, X.M. Yang, T.G. Luan, J. Chromatogr. A 1217, 6747 (2010)

14. M.E. Balmer, H.R. Buser, M.D. Muller, T. Poiger, Environ. Sci. Technol. 39, 953 (2005)

15. P. Cuderman, E. Heath, Anal. Bioanal. Chem. 387, 1343 (2007)

16. I. Tarazona, A. Chisvert, Z. León, A. Salvador, J. Chromatogr. A 1217, 4771 (2010)

17. S. Montesdeoca-Esponda, Z. Sosa-Ferrera, J.J. Santana-Rodríguez, Anal. Bioanal. Chem. 403, 867 (2012)

18. D.L. Giokas, A. Vasilios, V.A. Sakkas, T.A. Albanis, J. Chromatogr. A 1026, 289 (2004)

19. European Commission, Council Directive 76/768/EEC of 27 July 1976 and its successive amendments, Annex II

20. M. Krause, A. Klit, M.B. Jensen, T. Soeborg, H. Frederiksen, M. Schlumpf, W. Lichtensteiger, N.E. Skakkebaek, K.T. Drzewiecki, Int. J. Androl. 35, 424 (2012)

21. M. Schlumpf, P. Schmid, S. Durrer, M. Conscience, K. Maerkel, M. Henseler, M. Gruetter, I. Herzog, S. Reolon, R. Ceccatelli, O. Faass, E. Stutz, H. Jarry, W. Wuttke, W. Linchtensteiger, Toxicology 205 , 113 (2004)

22. P.Y. Kunz, H.F. Galicia, K. Fent, Toxicol. Sci. 90, 349 (2006)

23. A. Sanches-Silva, C. Andre, I. Castanhera, J.M. Cruz, S. Pastorelli, C. Simonea, P. PaseiroLosada, J. Agric. Food Chem. 57, 9516 (2009)

24. M.G. Pintado-Herrera, E. González-Mazo, P.A. Lara-Martín, Anal. Bioanal. Chem. 405, 401 (2013)

25. R. Rodríguez-Gómez, I. Jiménez-Díaz, A. Zafra-Gómez, O. Ballesteros, A. Navalón, Talanta 130, 561 (2014)

26. I. Jiménez-Díaz, L.M. Iribarne-Durán, O. Ocón, E. Salamanca, M.F. Fernández, N. Olea, E. Barranco, J. Chromatogr. B 1035, 57 (2016)
27. J.O. Straub, Toxicol. Lett. 131, 29 (2002)

28. K. Fent, A. Zenker, M. Rapp, Environ. Pollut. 158, 1817 (2010)

29. H.K. Jeon, Y. Chung, J.C. Ryu, J Chromatogr A 113, 192 (2006)

30. E. Damiani, W. Baschong, L. Greci, J. Photochem. Photobiol. B Biol. 87, 95 (2007)

31. M. Schlumpf, B. Cotton, M. Conscience, V. Haller, B. Steinmann, W. Lichtensteiger, Environ. Health Perspect. 109, 239 (2001)

32. P. Walden, Bull. Acad. Imper. Sci. (St Petersburg) 1800, 405-422 (1914)

33. D. Inman, D.G. Lovering, Ionic Liquids. (Plenum Press, New York, 1981)

34. J.S. Wilkes, Green Chem. 4, 73 (2002)

35. J.L. Atwood, J.D. Atwood, Advances in Chemistry Series No. 150. (American Chemical Society, Washington, 1976), pp 112-127

36. U. Domańska, in Ionic Liquids in Chemical Analysis, ed. by M. Koel. General Review of Ionic Liquids and Their Properties (Taylor and Francis Group, Boca Raton, 2009) pp. 1-71

37. J.M. Kokosa, Advances in solvent-microextraction techniques. Trends Anal. Chem. 43, 2 (2013)

38. N.V. Plechkova, K.R. Seddon, Chem. Soc. Rev. 37, 123 (2008)

39. A. Chisvert, J.L. Bened e, J.L. Anderson, S.A. Pierson, A. Salvador, Anal. Chim. Acta 983, 130 (2017)

40. C.Yao, J.L.Anderson, Anal. Bioanal. Chem. 395, 1491 (2009)

41. J. Lopez-Darias, V. Pino, J.H. Ayala, Microchim. Acta 174, 213 (2011)

42. A. Zgoła-Grzeskowiak, Anal. Methods 7, 1076 (2015)

43. E. Stanisz, A. Zgoła-Grześkowiak, Talanta 115, 178 (2013)

44. B. Delgado, V. Pino, J.L. Anderson, J.H. Ayala, A.M. Afonso, Talanta 99, 972 (2012)

45. T. Li, M.D. Josh, D.R. Ronning, J.L. Anderson, J. Chromatogr. A 1272, 8 (2013)

46. J. Zhang, M. Li, M. Yang, B. Peng, Y. Li, W. Zhou, H. Gao, R. Lu, J. Chromatogr. A 1254, 23 (2012)

47. Y. Liu, E. Zhao, W. Zhu, J. Chromatogr. A 1216, 885 (2009)

48. M. Baghdadi, F. Shemirani, Anal. Chim. Acta 634, 186 (2009)

49. H. Bagheri, O. Zandi, A. Aghakhani, Chromatographia 74, 483 (2011)

50. Y.R. Song, S.L. Zhao, P. Tchounwou, Y.M. Liu, J. Chromatogr. A 1166, 79 (2007)

51. G.Y. Zhao, S.J. Song, C. Wang, Q.H. Wu, Z. Wang, Anal. Chim. Acta 708, 155 (2011)

52. M. Mei, X. Huang, J. Chromatogr. A 1525, 1 (2017)

53. L. Vidal, A. Chisvert, A. Canals, A. Salvador, Talanta 81, 549 (2010)

54. A.L. Oenning, D. Lopes, A.N. Dias, J. Merib, E. Carasek, J. Sep. Sci. 40, 4431 (2017)

55. D. Ge, H.K. Lee, J. Chromatogr. A 1229, 1 (2012)

56. Y. Zhang, H.K. Lee, Anal. Chim. Acta 750, 120 (2012)

57. L.-K. Xue, W.-M. Ma, D.-X. Zhang, X.-Z. Du, Anal. Methods 5, $4213(2013)$

58. Y.-C. Ku, M.-I. Leong, W.-T. Wang, S.-D. Huang, J. Sep. Sci. 36, $1470(2013)$

59. R. Suarez, S. Clavijo, J. Avivar, V. Cerd, Talanta 148, 589 (2016)

60. J. Pernak, M. Smiglak, S.T. Griffin, W.L. Hough, T.B. Wilson, A. Pernak, J. Zabielska-Matejuk, A. Fojutowski, K. Kitad, R.D. Rogers, Green Chem. 8, 798 (2006)

61. X. Liu, Z. Ma, J. Xing, H. Liu, J. Magn. Magn. Mater. 270, 1 (2004)

62. L. Yan, L. Haifang, L. Jin-Ming, Talanta 77, 1037 (2009)

63. E.K. Paleologos, D.L. Giokas, M.I. Karayannis, Trends Anal. Chem. 24, 426 (2005)

64. R.P. Paradkar, R.R. Wiliams, Anal. Chem. 66, 2752 (1994)

65. P.P. Zhang, Z.G. Shi, Q.W. Yu, Y.Q. Feng, Talanta 83, 1711 (2011)

66. J.L. Benedé, A. Chisvert, D.L. Giokas, A. Salvador, J. Chromatogr. A 1362, 25 (2014)

67. J. Lei Ye, X. Liu, Y. Yang, L. Peng, Xu, J. Sep. Sci. 34, 700 (2011)

68. R. Suárez, S. Clavij, J. Avivar, V. Cerdà, Talanta 148, 589 (2016) 
69. P. Gonzalez-Hernandez, V. Pino, J.H. Ayala, A.M. Afonso, Anal. Methods 7, 1825 (2015)
70. T.E. Wang, M. Guo, W.L. Song, Y.D. Zhang, X.Z. Du, Anal. Methods 7, 3385 (2015) 